\title{
ESTEREÓTIPOS DE GÊNERO NA ASSISTÊNCIA AO HOMEM COM CÂNCER: DESAFIOS PARA A INTEGRALIDADE
}

\author{
GENDER STEREOTYPES IN THE CARE GIVEN TO MEN WITH CANCER: CHALLENGES TO INTEGRALITY \\ ESTEREOTIPOS DE GÉNERO EN LA ASISTENCIA AL HOMBRE CON CÁNCER:DESAFÍOS PARA \\ LA INTEGRALIDAD
}

\author{
Alberto Mesaque Martins ${ }^{1}$ \\ Celina Maria Modena ${ }^{2}$
}

Resumo Na perspectiva da pesquisa qualitativa e das teorias de gênero, este estudo tem como objetivo identificar e analisar as concepções de profissionais de saúde que atuam em uma equipe multidisciplinar em oncologia acerca da assistência oferecida ao público masculino com câncer. Foram entrevistados dez profissionais de saúde que compõem uma equipe multidisciplinar de um hospital oncológico de Belo Horizonte, em Minas Gerais. Os resultados indicam que, para os entrevistados, os homens configuram-se como um público resistente e de difícil atuação, exigindo um manejo distinto daquele oferecido às mulheres. A dimensão biológica e o processo de socialização foram apontados como elementos que contribuem para esse distanciamento. Constatou-se ainda que os discursos dos profissionais de saúde também se encontram atravessados por estereótipos de gênero. Observam-se maior ênfase às necessidades das mulheres e o não reconhecimento dos homens como sujeitos das políticas de saúde e ações assistenciais. Faz-se necessária a inclusão do tema das masculinidades na pauta de discussões dos serviços de saúde em oncologia, favorecendo a construção participativa de estratégias que possibilitem o reconhecimento das necessidades masculinas e a garantia de práticas de saúde orientadas pelo princípio da integralidade.

Palavras-chave neoplasias; gênero; saúde do homem; assistência.
Abstract Based on qualitative research and on the perspective of gender theory, this study aims to identify and analyze the views health professionals working in a multidisciplinary team in oncology have of the care provided to male cancer patients. Ten health professionals that make up a multidisciplinary team at a cancer hospital in Belo Horizonte, Minas Gerais, Brazil, were interviewed. The results indicate that, to the respondents, men are a resistant, hard-to-work-with audience, requiring a different type of management than that provided to women. The biological dimension and the socialization process were singled out as factors that contribute to this gap. It was further observed that the health professionals' discourses are also crossed by gender stereotypes. Greater emphasis was placed on women's needs and on the nonrecognition of men as subjects of health and welfare action policies. It is necessary to include the masculinity topic in the oncology health service discussion agenda, favoring a participatory construction of strategies that enable the recognition of men's needs and ensure health practices guided by the principle of comprehensiveness.

Keywords cancer; gender; men's health; care. 


\section{Introdução}

Nos últimos anos, observa-se o desenrolar de um importante processo de reorientação dos modelos assistenciais em saúde e das práticas de cuidado, exigindo dos profissionais e gestores novos modos de pensar, sentir e agir (Bedrikow e Campos, 2011). Cada vez mais, constata-se que o Sistema Único de Saúde (SUS) não se refere a uma proposta concluída e definitiva. Trata-se de um projeto político ainda em construção que sofre influências do contexto sócio-histórico e dos sujeitos que o constituem (Souza, 2009).

No cenário brasileiro, Campos (2003) chama a atenção para a coexistência de pelo menos três modelos assistenciais em saúde, pautados em distintas concepções de clínica e alicerçados em propostas de cuidado diferenciadas. O primeiro modelo é denominado pelo autor como 'clínica oficial ou tradicional', marcada pela dominação do saber biomédico e positivista que reduz o sofrimento dos indivíduos a um conjunto de sintomas anatômicos e fisiológicos que devem ser descritos, medicalizados e tratados. Nesse modelo, não há espaço para manifestação dos sujeitos, da sua história de vida, seus desejos e demandas. Apenas a doença como entidade biológica é percebida como o foco das intervenções em saúde (Campos, 2003; Bedrikow e Campos, 2011).

Já o segundo modelo é denominado por Campos (2003) como a 'clínica degradada', tendo em vista que nele as propostas de cuidado encontram-se atravessadas por numerosos dificultadores, como a precarização do trabalho em saúde, o sofrimento e o adoecimento dos trabalhadores, a incipiência de recursos físicos e humanos, a ineficiência de políticas e programas governamentais, dentre outros, que reduzem a autonomia e a capacidade resolutiva das equipes de saúde.

Tais modelos vêm se mostrando insustentáveis diante das novas demandas apresentadas pelos sujeitos contemporâneos aos profissionais e gestores em saúde, revelando que a prática do cuidado refere-se a um fenômeno complexo e multifacetado (Campos, 2003; Cecílio, 2011). Desse modo, a expressão e o reconhecimento de necessidades subjetivas e sociais exigem das equipes um novo olhar e uma nova atuação para a qual a proposta tradicional não se encontra aberta e instrumentalizada (Bedrikow e Campos, 2011).

É nessa direção que Campos (2003) aponta para a urgência de uma reforma dos modelos assistenciais em saúde e alerta para a necessidade da reorientação das práticas de cuidado, propondo assim a construção coletiva de uma nova clínica, desta vez ampliada e que traga em sua centralidade não as doenças, mas os sujeitos em sua totalidade. A 'clínica ampliada' ou a 'clínica do sujeito' propõe, portanto, a inclusão de novos temas na pauta de cuidados, ampliando o olhar dos profissionais de saúde para além da dimensão biológica e do corpo adoecido, estimulando-os a considerar os usuários e trabalhadores do SUS como sujeitos sociais que carregam para as organiza- 
ções de saúde suas histórias, crenças, valores, desejos e afetos (Bedrikow e Campos, 2011; Cecílio, 2011).

Essa proposta de clínica, ainda hoje instituinte no cenário brasileiro, encontra-se intimamente articulada aos princípios estruturantes do SUS, sobretudo no que se refere à integralidade da assistência (Campos, 2003; Camargo Junior, 2010). De modo a garantir a efetividade desse princípio, políticas e programas de saúde vêm sendo propostos alicerçados em novos paradigmas, abrindo espaço para a problematização acerca dos determinantes sociais da saúde, especialmente no que se refere a cor/raça, classe social e gênero (Mattos, 2009; Bedrikow e Campos, 2011).

É nesse contexto de transformação dos modos de pensar e agir em saúde que foi instituída, em 2009, a Política Nacional de Atenção Integral à Saúde do Homem (PNAISH), ${ }^{3}$ que enfatiza a necessidade de planejamento de práticas assistenciais que considerem as singularidades do público masculino como sujeitos históricos e o desenvolvimento de ações que contribuam para a melhoria das condições de saúde dessa população (Brasil, 2009).

Apesar de se configurar como uma proposta de vanguarda, a primeira política pública de saúde voltada, especificamente, para a população masculina no contexto latino-americano, a PNAISH também carrega marcas do contexto sócio-histórico, político e cultural no qual foi construída e institucionalizada. Diversos autores vêm alertando para a necessidade de se considerar a multiplicidade de discursos e interesses que compõem e atravessam o texto da PNAISH (Carrara, Russo e Faro, 2009; Martins e Malamut, 2013, Müller, 2012, 2013).

Martins e Malamut (2013) destacam a presença marcante dos discursos biomédicos e epidemiológicos no texto da PNAISH, recorrentes no modelo de clínica tradicional, revelando um processo ora de vitimização, ora de culpabilização da população masculina pelo próprio adoecimento. Carrara, Russo e Faro (2009) ressaltam que, ao mesmo tempo que se apresenta como uma nova política de saúde, a PNAISH evidencia jogos de interesses em prol da medicalização dos corpos masculinos que, até então, escapavam ao controle e biopoder das instituições e equipes de saúde. Na mesma direção, Aquino (2005) afirma que, apesar de os estudos em saúde do homem trazerem novas contribuições para a temática de gênero e saúde, a área ainda é composta por um grande número de estudos relacionados às enfermidades do aparelho genital e urológico, em especial a disfunção erétil, evidenciando fortes interesses pela medicalização da sexualidade masculina.

Tendo em vista o aumento da incidência e prevalência dos diferentes tipos de cânceres entre os homens brasileiros, bem como as elevadas taxas de morte por essa enfermidade, a PNAISH vem incentivando o desenvolvimento de ações de prevenção, diagnóstico precoce e tratamento das neoplasias (Brasil, 2009). Entretanto, essas estratégias ainda se deparam com 
barreiras como aquelas relacionadas ao processo de socialização dos homens, especialmente no que se refere às relações de poder entre gêneros, e ainda na maneira como os serviços de saúde são pensados e estruturados (Brasil, 2009; Mesquita, Moreira e Maliski, 2011).

Apesar dos esforços recentes para transformação desse cenário, as práticas de cuidado ainda são associadas por profissionais e gestores de saúde como um atributo restrito às mulheres (Lago e Müller, 2010). Da mesma forma, os comportamentos de risco e 'não cuidado' são comumente associados aos homens de forma pouco crítica, determinista e naturalizada (Soares e Laranjeira, 2010). Tais concepções orientam os modos de pensar, sentir e agir dos profissionais que atuam nas equipes de saúde, podendo se refletir nas ações oferecidas e até mesmo negadas e silenciadas (Machin et al., 2011).

Nessa perspectiva, o estudo teve como objetivo identificar e analisar as concepções de profissionais de saúde que atuam em uma equipe multidisciplinar em oncologia acerca da assistência oferecida ao público masculino com câncer.

\section{Desenvolvimento do estudo e método}

O estudo 4 foi realizado sob a perspectiva da pesquisa qualitativa, que, segundo Minayo (2007), possibilita a análise do fenômeno de saúde/adoecimento em diversas perspectivas, valorizando a compreensão dos diferentes saberes e crenças e considerando os valores e as representações que os sujeitos atribuem às ações de saúde, bem como os sentidos e significados que associam às práticas de cuidado.

O referencial teórico que orientou a pesquisa foram as teorias de gênero, sobretudo os estudos sobre a relação entre as masculinidades e os cuidados em saúde (Connel, 1995; Gomes, 2008). Segundo Scott (1995, p. 86), gênero refere-se a "um elemento constitutivo de relações sociais baseadas nas diferenças percebidas entre os sexos e (...) uma forma primária de dar significado às relações de poder".

Essa perspectiva teórica e também política é apontada como importante dispositivo de análise dos jogos ideológicos e de poder que colaboram para a transformação das diferenças sexuais entre homens e mulheres em instrumentos de dominação e desigualdades sociais (Scott, 1995). No campo da saúde coletiva, os estudos de gênero vêm cooperando com a análise crítica das implicações do processo de socialização e construção das identidades masculinas e femininas na maneira como os sujeitos se vinculam aos serviços de saúde e práticas de cuidado ou se distanciam deles (Aquino, 2006; Villela, Monteiro e Vargas, 2009; Marques, 2010; Schraiber, 2012) e, ainda, dos diferentes modos como tais concepções interferem nos modos de pensar, 
sentir e agir de profissionais de saúde em relação às práticas assistenciais (Toneli, Souza e Müller, 2010; Machin et al., 2011).

Cada vez mais se reconhece que a categoria gênero não se encontra restrita ao âmbito dos usuários, mas refere-se a um elemento estruturante dos modos de pensar, sentir e agir das equipes e gestores em saúde, delineando as propostas assistenciais ofertadas ou silenciadas, forjando assim os sujeitos das políticas e dos programas de saúde (Marques, 2010; Machin et al., 2011). Conforme destaca Schraiber (2012), o trabalho em saúde também se refere a uma prática social, de modo que as organizações de saúde constituem-se como um palco privilegiado para manifestação e (re)produção das desigualdades de gênero, frequentemente despercebidas, negadas ou silenciadas. Desse modo, os serviços de saúde passam a ser percebidos como instituições 'genderizadas' (Soares e Laranjeira, 2010; Toneli e Müller, 2011).

Nessa mesma perspectiva, Scott (1995) também chama a atenção para a necessidade de se considerar que as questões de gênero extrapolam as relações familiares e de parentescos. A autora ressalta que elas estão presentes e são (re)produzidas por diferentes instituições, dentre elas aquelas voltadas para o cuidado em saúde. Conforme destaca a autora, o gênero "é construído igualmente na economia e na organização política, que, pelo menos em nossa sociedade, operam atualmente de maneira amplamente independente do parentesco" (Scott, 1995, p. 87).

Conforme destacam Connel e Messerschmidt (2013), é necessário considerar uma multiplicidade de possibilidades de se pensar e exercer a masculinidade, de maneira que diferentes contextos e tempos históricos (re)produzem distintos modos de 'ser homem', apontando a necessidade de se pensar em masculinidades, sempre no plural. Apesar do seu caráter dinâmico, mutável e diversificado, Connel (1995) destaca a existência de um modelo de masculinidade hegemônica, fortemente difundido e idealizado nas culturas ocidentais. Nesse modelo, os homens são representados como indivíduos fortes e invulneráveis, contribuindo para o delineamento de relações hierárquicas de poder que legitimam o processo de dominação deles sobre as mulheres e, também, sobre outros grupos de homens que se orientam por outros padrões de masculinidade, como, por exemplo, os homossexuais (Kimmel, 1998).

Assim, foram realizadas entrevistas orientadas por um roteiro semiestruturado com profissionais que integram uma equipe multidisciplinar de saúde de um hospital público-beneficente referência na assistência oncológica localizado na cidade de Belo Horizonte (Minas Gerais). O roteiro esteve alicerçado no relato das práticas assistenciais desenvolvidas, nas concepções acerca do processo de adoecimento masculino por câncer e na maneira como os entrevistados percebem a assistência a essa população.

Os participantes foram selecionados com base na técnica de bola de neve. Foi identificado um primeiro participante de acordo com os seguintes 
critérios de inclusão: ser profissional de saúde, atuar na assistência oncológica no serviço selecionado, ter experiência profissional superior a três anos e disponibilidade para participar da entrevista. Em seguida, cada participante indicava outro membro da equipe que também preenchesse os critérios de inclusão. O número de participantes foi determinado com base nos critérios de saturação do discurso propostos por Fontanella, Bicas e Turato (2008), em que o pesquisador suspende a inclusão de novos participantes quando as narrativas coletadas passam a apresentar redundância ou repetição.

No final, foram entrevistados dez profissionais de saúde: uma enfermeira, uma médica, uma farmacêutica, um nutricionista, uma fonoaudióloga, um assistente social, um fisioterapeuta, um técnico em radiologia e dois técnicos de enfermagem. Dentre os entrevistados, oito são do sexo feminino, e a idade média dos entrevistados foi de 31 anos. Eles atuam em média há oito anos no âmbito da oncologia.

As entrevistas foram realizadas em locais e horários indicados pelos próprios participantes e tiveram duração média de quarenta minutos. Apenas um profissional optou por ser entrevistado em um espaço externo ao hospital. Tais entrevistas foram gravadas, transcritas e analisadas na perspectiva da análise de conteúdo (Bardin, 1976). Realizou-se uma leitura exaustiva do material transcrito, possibilitando assim a identificação de categorias temáticas e unidades de significado que subsidiaram a interpretação dos dados e a construção dos resultados (Bardin, 1976).

Os participantes foram esclarecidos sobre os objetivos da pesquisa e em seguida assinaram o termo de consentimento livre e esclarecido. O projeto de pesquisa foi submetido ao Comitê de Ética e Pesquisa com Seres Humanos do Centro de Pesquisas René Rachou, da Fundação Oswaldo Cruz, e aprovado sob o parecer n. 13/2010. Para garantir o anonimato dos entrevistados, seus nomes foram substituídos pela sigla ' $\mathrm{P}$ ', referindo-se a 'profissional', seguida do número de identificação.

\section{Os homens e sua relação com o tratamento oncológico}

A análise dos dados apontou para as seguintes categorias temáticas: concepções dos profissionais de saúde sobre a relação dos homens com o tratamento oncológico e as implicações de gênero nas práticas assistenciais das(os) profissionais.

As falas das(os) entrevistadas(os), alicerçadas em suas vivências pessoais e experiências de trabalho nos serviços especializados em oncologia, indicam a percepção de singularidades na maneira como os homens vivenciam o adoecimento por câncer e se vinculam à assistência oncológica. Para elas/eles, os homens referem-se a um público distante dos serviços de saúde, 
apresentando maior procura por cuidados em situações de doença já manifesta e em estado avançado de adoecimento. Nesse sentido, duas entrevistadas afirmam: “Culturalmente, eu tenho a impressão que o homem só procura o médico quando adoece" (P. 5); “O homem só vai ao médico quando ele tá morrendo, com dor. Ele não gosta de médico, não gosta de tomar remédio" (P. 9).

A dificuldade de mobilização da população masculina para os serviços e ações de saúde, sobretudo no que se refere às práticas preventivas, vem sendo apontada na literatura como um grande desafio ainda a ser superado (Gomes, 2008; Brasil, 2009; Couto e Gomes, 2012). Estudos ressaltam a incipiente adesão dos homens às ações ofertadas no âmbito da atenção básica e maior procura por atendimentos em serviços de urgência e emergência, sobretudo os prontos-socorros (Figueiredo e Schraiber, 2011; Gomes et al., 2011). O mesmo parece se repetir no contexto da oncologia. Estudos realizados em diferentes regiões do Brasil também constataram a busca tardia pelo diagnóstico e tratamento oncológico (Mesquita, Moreira e Maliski, 2011; Burille, Schwartz e Zillmer, 2013; Modena et al., 2014).

Conforme pode ser observado nas falas a seguir, os sentidos que os homens atribuem ao 'ser-homem', construídos e reforçados socialmente, foram apontados pelas(os) entrevistadas(os) como elementos estruturantes desse distanciamento:

O homem tem aquela tendência, aquela postura que ele é completo. Ele não precisa de alguém pra cuidar dele. (...) Ele é autossuficiente, ele é produtivo, ele é capaz de transformar situações (P. 3).

O homem tende a ser mais durão! Ele tende a não expor sentimentos, mesmo sob orientação. Ele não expõe a dor que está sentindo, ele recebe a orientação do tratamento sem se expor muito (P. 10).

Esses achados corroboram outros estudos que também ressaltaram que os modos como os homens concebem a masculinidade podem interferir na busca ou distanciamento das práticas de cuidado (Mesquita, Moreira e Maliski, 2011; Burille, Schwartz e Zillmer, 2013).

Ainda segundo as(os) entrevistadas(os), os homens também apresentam dificuldades de aderir às ações ofertadas pelas equipes de saúde e dar continuidade à proposta de tratamento oncológico, dificultando assim a construção de vínculo e a manutenção dos cuidados. Para caracterizar os homens, as(os) participantes recorreram a adjetivos como 'desobedientes' e 'resistentes'. Em contraposição, as mulheres foram representadas como sujeitos disciplinados, com maior capacidade de persistência e mais disponíveis ao tratamento oncológico do que os homens. Algumas participantes afirmaram: 
Eles realmente têm a tendência a desistir, desanimar mais fácil. Faltam mais, né?! Quando você faz umas requisições do tipo "Não pode fumar", "Não pode beber", "Não pode fazer isso", o homem, ele é mais desobediente. Isso dificulta! O homem tem mais resistência (P. 1).

Então a mulher, quando a gente fala com ela: "A senhora tem que se alimentar melhor, porque é um tratamento", eu acho que ela escuta mais e ela tenta seguir essas orientações de uma melhor forma. (...) Ela aceita mais, ela se resigna mais e permite que o cuidado chegue até ela de uma melhor forma do que o homem (P. 7).

Tratando-se das sociedades ocidentais, sobretudo a latino-americana, os homens ainda são incentivados a perseguir e exercitar um modelo de masculinidade pautado em estereótipos como força física, coragem, determinação e invulnerabilidade, abrindo pouco espaço para expressão de fragilidades ou preocupações com a saúde (Gomes, 2008). Desse modo, ser homem de verdade, na cultura brasileira, ainda se mostra incoerente com o exercício do cuidado da saúde. Por sua vez, o cuidado de si e dos outros passa a ser reconhecido socialmente como um atributo destinado às mulheres, revelando o processo de divisão sexual do cuidado (Toneli e Müller, 2011). É preciso ressaltar que tais estereótipos de gênero não se constituem como uma singularidade dos usuários do SUS. Como sujeitos históricos, profissionais e gestores em saúde, também se encontram atravessados por estereótipos, e seus modos de pensar, sentir e agir em saúde estão impregnados e marcados pelas questões de gênero (Schraiber, 2012).

Conforme ressaltaram as(os) entrevistadas(os), desde crianças as mulheres são estimuladas a observar seu corpo e cuidar dele, incentivadas às práticas de cuidado, contribuindo para maior familiaridade com a rotina e singularidades das instituições de saúde. Ao contrário das mulheres, os homens são incentivados a enfrentar os sintomas e agravos de forma heroica e solitária. Apenas quando não mais resistem ao sofrimento, recebem autorização social para a busca de auxílio de uma equipe de saúde. A fala de uma das entrevistadas ilustra essa concepção, também presente no discurso de outras(os) participantes:

A mulher é acostumada a ir ao ginecologista todo ano, fazer exame preventivo. (...) A mulher começa a menstruar aí com quatorze, quinze anos, já começa a ter uma orientação. Daí um tempo, quando engravida, tem que ir ao ginecologista mesmo, tem que fazer o pré-natal. Depois, quando vai ganhar o bebê, não tem outro jeito, tem que buscar, e o homem não (P. 5).

Assim, diante da facticidade do adoecimento pelo câncer e, ao se depararem com a necessidade do tratamento oncológico, os homens são levados 
a (re)construir suas representações, alterar comportamentos e ressignificar o modo de exercitar sua masculinidade. Resultados semelhantes vêm sendo identificados na literatura nacional e internacional, revelando que, após o diagnóstico de câncer, os homens veem-se confrontados com suas limitações e fragilidades, até então negadas e negligenciadas, o que produz uma ruptura em sua biografia e a reformulação dos projetos de vida (Dazio, Sonobe e Zago, 2009; Kelly, 2009; Gannon et al., 2010; Martins et al., 2013; Modena et al., 2014).

Para as(os) entrevistadas(os), tal movimento de mudança é vivenciado por grande angústia, tendo em vista que o adoecimento e a nova condição de paciente se contrapõem aos padrões difundidos pelo modelo de masculinidade hegemônica, perseguido e idealizado por esse grupo. Um dos entrevistados afirma: “Então, para o homem, isso [adoecer] é um choque imenso! Ele ficar na postura de paciente. É como se ele estivesse já inválido (...). Então ele se sente arrasado, incapaz de voltar a ser homem!" (P. 3).

As(Os) participantes também destacaram que a fragilidade imposta pelo adoecimento e a necessidade constante de cuidados exigem uma reformulação nos papéis sociais nas famílias e, consequentemente, incidem na necessidade de redistribuição do poder. Nessa perspectiva, os homens passam a ocupar uma posição de passividade e assujeitamento, socialmente atribuídos às mulheres, enquanto estas, por sua vez, passam a se ver como responsáveis pela provisão financeira e proteção material da família. Um dos entrevistados afirma: "Aí faz aquela inversão: as mulheres ficam na postura do homem aqui fora e o homem fica na postura da mulher lá dentro. $\mathrm{O}$ homem fica mais reservado, há uma inversão de postura, de colocação, de reação" (P. 3).

Estudos indicam que, ao adentrarem o hospital, os homens se deparam com um novo universo, desconhecido e não familiar, favorecendo a manifestação de ansiedade intensa e sensação de perda ou redução da autonomia (Xavier et al., 2010; Martins et al., 2013; Burille, Schwartz e Zillmer, 2013; Modena et al., 2014). Deve-se considerar que, ainda hoje, grande parte dos serviços de saúde encontra-se alicerçada no modelo clínico tradicional, segundo o qual pouco espaço é dado para a expressão de suas necessidades psicossociais (Bedrikow e Campos, 2011). Conforme destaca Silva (2009), é recorrente que os sujeitos adoecidos sejam reduzidos a um órgão acometido por neoplasias, privados não apenas de seus nomes e pertences pessoais, mas, sobretudo, das suas identidades e singularidades, conforme atesta um dos participantes: "Ele fica abatido, porque ele já começa a pensar da seguinte forma: 'No meu cantinho, eu levanto todo dia tantas horas! Aqui eu sou obrigado a tomar banho pela manhã!'; 'Você chega e pergunta pra mim se eu aguento ir andando ou não! Eu não tô morto!'” (P. 3).

As(Os) entrevistadas(os) também chamaram a atenção para o impacto das mudanças corporais, como perda de peso, inchaço, alopecia, dentre outras, na autoestima dos homens hospitalizados. Apesar dos avanços nas propostas 
terapêuticas para o tratamento das neoplasias, esse processo ainda é marcado por desgastes físicos e psíquicos. Segundo os relatos das(os) profissionais, é recorrente que os homens, antes distantes das organizações de saúde, se defrontem com uma densa rotina de exames, consultas e internações. Em muitos casos é necessária a realização de procedimentos invasivos e ingestão de drogas e medicamentos com efeitos colaterais indesejáveis.

As(Os) profissionais também destacaram que, durante o processo de adoecimento e tratamento oncológico, o corpo masculino vai sendo gradativamente desconfigurado. Nessa direção, um dos entrevistados afirmou: “Ficam extremamente revoltados, porque é mesmo o corpo sendo desconstituído, em processo de 'acabamento' mesmo, muitas vezes com cheiros, assim, terríveis, incapazes de alguém conseguir ficar próximo! É muito difícil!" (P. 3). Assim, o corpo másculo, forte e invulnerável idealizado pelos homens ocidentais vai dando espaço a uma nova corporeidade que denuncia essa suposta invulnerabilidade e atesta contra ela.

É preciso considerar que o corpo é mais do que um conjunto de órgãos e tecidos. Conforme destaca Jardim (1995), ele deve ser compreendido como um suporte de significados sociais atribuídos por um grupo específico. Em sua dimensão simbólica, o corpo masculino configura-se como um produto histórico e cultural, forjado mediante concepções que o associam à força física, à invulnerabilidade e à capacidade ativa e produtiva. No dizer de Butler (2011), o corpo carrega consigo discursos e ideologias como seu próprio sangue, portanto, atravessado e marcado pelos modos de produção da existência. Transformado durante o processo de adoecimento e tratamento oncológico, essa nova corporalidade exige dos homens uma reconstrução de sua masculinidade e a ressignificação dos sentidos a ela atribuídos.

Outra mudança significativa constatada pela equipe de profissionais refere-se ao impacto do adoecimento e do tratamento oncológico no exercício da sexualidade dos homens. As(Os) entrevistados ressaltam que a tristeza intensa que perpassa o processo de diagnóstico de câncer - bem como a rotina hospitalar, os procedimentos cirúrgicos e medicações utilizadas no tratamento das neoplasias - contribui para a manifestação de impotência sexual e dificuldades de ereção.

Diante da capacidade de realização do ato sexual comprometida, é recorrente que os homens vivenciem sentimentos de perda ou redução de sua virilidade. Tratando-se das culturas ocidentais, sobretudo a latino-americana, os homens são estimulados desde meninos a se mostrarem prontos e disponíveis para os jogos de sedução e atividades sexuais, tendo o pênis ereto como o principal signo atestador de sua masculinidade. Conforme se observa a seguir, no relato das entrevistadas, ao se depararem com as dificuldades de ereção, os homens passam a se defrontar com sentimentos de angústia, vergonha e o medo de perda da parceira: 
A gente sempre ouve algumas coisas assim: “Ó, agora o negócio [pênis] não vai funcionar" (...) Então a grande dificuldade, eu acho que é só essa: a relação sexual em si. Eles não se preocupam nem tanto com a doença e sim com o que vai acontecer depois. "Ah, eu sou casado, tinha uma vida sexual ativa, e agora? De repente, eu não vou conseguir!" (P. 4).

É bem complicado! Já tive paciente: “Ah, eu não vou fazer porque minha cirurgia... minha esposa é nova e fogosa!". O homem tinha setenta anos, setenta e seis, e a esposa tinha trinta, trinta e poucos. Ele não fez a cirurgia, ele fez a radioterapia, mas faleceu e a esposa ficou, entendeu?! (P. 9).

Cabe ressaltar que as falas desses profissionais também se encontram impregnadas por estereótipos de gênero. Nessa perspectiva, a capacidade erétil dos homens é tomada como sinônimo da própria masculinidade, como pode ser constatado nas falas a seguir: “O paciente vai receber um medicamento que ele vai tomar por via oral, de uso contínuo, que vai abaixar o nível de hormônio testosterona dele, e com isso a masculinidade dele cai, né?!" (P. 10, destaque nosso); "Dentro do meu trabalho que eu descobri que o coração de um homem bate em outro local! Não é em cima, no peito (...) Lá em baixo [pênis] (...) pra muitos homens, se a vida sexual deles acaba, pra eles a vida acabou!" (P. 9).

Esses dados revelam que profissionais e gestores de saúde também se constituem como sujeitos sócio-históricos e políticos, tendo sua prática profissional impregnada por discursos e ideologias que refletem marcas de uma cultura 'genderificada' (Machin et al., 2011). Embora frequentemente silenciadas, tais concepções de gênero materializam-se nas práticas assistenciais, incidindo assim nos modos de pensar, sentir e agir das equipes de saúde (Schraiber, 2012).

Analisando os significados acerca dos homens e masculinidades construídos por profissionais de um hospital-escola e gestores municipais e estaduais de saúde de Pernambuco, Lyra e colaboradores (2012) também constataram a dificuldade desses sujeitos de incluírem os homens na pauta assistencial da instituição. Os autores chamam a atenção para o fato de que as ideologias sexistas também se encontram difundidas e (re)produzidas nas instituições de saúde, interferindo assim no processo de trabalho em saúde.

Os estereótipos de gênero também podem ser constatados no discurso das(dos) entrevistadas(dos) acerca dos impactos do adoecimento e tratamento oncológico na sexualidade de homens e mulheres. Enquanto a redução da libido é percebida como um evento estressor e de difícil manejo para os homens hospitalizados, o mesmo fenômeno parece ser atenuado quando se refere às mulheres. A diminuição da libido é percebida pelos entrevistados como um fenômeno natural e aceitável para as pacientes do sexo feminino, 
revelando a forte associação da atividade sexual voltada para o prazer no âmbito do masculino e explicitando uma representação das mulheres como sujeitos castos, recatados e reprodutores. As falas de duas entrevistadas ilustram esse fenômeno:

Eu acho que isso pro homem tem um impacto muito maior do que pra mulher. A mulher já tem a fase da menopausa mesmo, independente de estar [doente]... Já é esperado que numa fase da vida a mulher tenha menopausa, que os hormônios mudem e que com o passar dos anos a atividade sexual vai mudar também, né?! Então, eu acho que as mulheres aceitam isso mais como um ciclo (P. 5).

Ele [homem] tende a abandonar o tratamento, mais do que uma mulher, que também faz uma ablação hormonal, que faz um efeito do tipo menopausa. Mesmo sendo uma mulher mais jovem, ela tolera mais viver aquela fase sem o hormônio, por mais que ela sinta todos aqueles efeitos de menopausa, que seria calores e ressecamento, ela tende a tolerar isso mais do que o homem (P. 10).

Analisando as falas das(dos) entrevistadas(os), observa-se que suas concepções acerca das singularidades que permeiam a assistência masculina encontram-se alicerçadas em pelo menos duas categorias. A primeira refere-se à implicação dos aspectos socioculturais, especialmente o processo de socialização e construção da identidade masculina, na manutenção do distanciamento dos homens dos serviços de saúde. Nessa perspectiva, as(os) participantes reconhecem que homens e mulheres são socializados em uma cultura marcada pelas desigualdades de gênero que delimitam os papéis sociais distintos em razão das diferenças sexuais e se mostram atravessadas pelas relações de poder, conforme as falas a seguir: “Tem até aquela questão, assim, de conservadorismo masculino mesmo. Aquele regime, assim, que o homem não pode fazer isso, porque num caso desse ele vai deixar de ser homem!" (P. 1); “Eu acho que é a própria cultura mesmo! A tendência da mãe é fazer tudo pro filho e muitas vezes, na educação, você não orienta seu filho a cuidar: 'Ah, homem não precisa dessas coisas! Homem que é homem não precisa!'” (P. 9).

Já a segunda categoria refere-se ao reconhecimento pelas(os) entrevistadas(os) de uma estrutura biológica, a-histórica, que contribuiria para o maior cuidado das mulheres e o descuidado dos homens. As falas de duas das entrevistadas ilustram essas concepções:

Eu acho que é da natureza mesma de cada um! Por mais que a gente queira e tenha emancipação da mulher, as outras coisas que a gente tenta igualar, tem diferença o homem da mulher! Então eu acho que é pela própria natureza mesmo (P. 2). 
Biologicamente, a mulher é mais reservada, ela tem os seus elementos. O homem é explosivo, ele se abre fácil pra uma série de coisas relativas ao corpo dele, a mulher é mais reservada, na biologia e na psicologia. A mulher, pra alcançar esse nível, ela precisa ser trabalhada, e um homem com poucos estímulos ele já está extravasando, né?! Penso assim (P. 5).

Essa concepção vem sendo identificada em outros estudos, denominada de essencialista, uma vez que negligencia a influência do processo de aspectos sócio-históricos como determinantes na constituição dos sujeitos (Scott, 1995; Arilha, 2010; Kuhnen, 2013). Ao negar a dimensão histórica, essa perspectiva abre espaço para ideologias que justificam e legitimam as desigualdades de gênero e minam os desejos e possibilidades de mudanças em prol das relações mais equitativas entre os sujeitos (Schraiber, 2012).

Resultados semelhantes foram identificados nos estudos de Martins e colaboradores (2012) e Knauth, Couto e Figueiredo (2012), que também indicam a recorrente utilização de explicações socioculturais e biológicas pelos profissionais de saúde para a explicação dos modos singulares pelos quais os homens se vinculam aos serviços de saúde. Os autores chamam a atenção para a importância de se retomar a historicidade dessas singularidades, problematizá-las nos espaços de formação em saúde, de modo que elas não sejam tomadas como determinantes imutáveis que apenas naturalizariam esse fenômeno.

Retomar a historicidade dos sujeitos da saúde, sejam usuários, sejam profissionais ou gestores, abre espaço para uma análise contextualizada e, ainda, para a possibilidade de construção de processos de mudança que favoreçam uma assistência à saúde integral e atenta às demandas e necessidades singulares de cada indivíduo. Tal reconhecimento, portanto, aponta para a urgência de se repensarem as estruturas organizacionais e as propostas de gestão dos serviços de saúde.

\section{As implicações de gênero nas práticas assistenciais}

Outra dimensão identificada no discurso das(os) entrevistadas(os) refere-se às implicações de gênero nas práticas assistenciais desses profissionais. Embora reconheçam as singularidades nos modos como os homens vivenciam o adoecimento pelo câncer e a maneira distinta pela qual se vinculam ao tratamento oncológico, as falas das(os) entrevistadas(os) revelam um silenciamento das questões de gênero em seu cotidiano de trabalho.

Após serem hospitalizados, os homens passam a ser percebidos pela equipe como 'pacientes', negligenciando assim todo o processo de construção social de seus modos de ser, pensar e agir. Apesar dos esforços em 
prol de uma assistência humanizada, ainda persistem serviços em que os sujeitos passam por um processo de despersonalização, passando a ser reconhecidos não mais por suas histórias coletivas e individuais, mas sim pelas características das patologias que os acometem (Bedrikow e Campos, 2011). Nesse contexto de negação histórica dos sujeitos, as questões de gênero parecem não encontrar espaço para se manifestar, como revela a fala de uma das entrevistadas ao constatar que "às vezes o paciente da saúde ele não tem sexo" (P. 9).

A negação e o silenciamento das questões de gênero nas práticas assistenciais vêm sendo destacados em diversos estudos, sob a denominação gender blindness (Marques, 2010). Embora presentes em todas as relações sociais, profissionais e gestores ainda encontram dificuldades para reconhecer e manejar as questões de gênero nas instituições de saúde (Aquino, 2006; Villela, Monteiro e Vargas, 2009). Segundo Schraiber (2012), a invisibilidade do tema nesses espaços encontra-se intimamente relacionada aos modelos clínicos tradicionais, pautados em concepções biomédicas e tecnicistas que desconsideram a historicidade dos usuários e dos profissionais de saúde.

Cabe ressaltar que esse fenômeno não se restringe apenas à assistência. É também marcante nos processos de formação dos profissionais de saúde. Ainda persiste a dificuldade de se incorporar nos currículos acadêmicos e nas propostas de educação permanente a discussão da temática de gênero, muitas vezes reduzida a discussões acerca dos aspectos biomédicos do sexo e da sexualidade dos indivíduos, de forma binária e pouco contextualizada (Aquino, 2006; Schraiber, 2012).

Ao recordar sua formação profissional, um dos entrevistados aponta para a associação dos pacientes ao boneco utilizado como modelo anatômico nos cursos de formação de profissionais de saúde. Ao contrário dos pacientes 'reais', o boneco revela-se como um ser híbrido que ora mostra-se como homem - já que possui um pênis - ora, em outros momentos, como uma mulher - assim denominado pela constatação da presença da vagina. Tal analogia parece estar associada à ideia, ainda muito marcante, de que profissionais de saúde e usuários 'não possuem sexo', legitimando assim o silenciamento da temática de gênero e suas implicações políticas tanto na formação como no âmbito da assistência profissional, como pode ser observado a seguir:

Inclusive a gente brinca que tem o boneco por nome João (...). Mas o João, ao mesmo tempo que ele tem um pênis, de repente ele já muda e já passa a ter uma vagina (...) Na enfermagem não há sexo, há o necessitado (...). Eu tive uma professora, ela era bem contundente: (...) “É uma pessoa que precisa de mim! Ele precisa de mim! Então eu preciso esquecer que ele tem um pênis ou que tem uma vagina, que tem seios ou não!" (P. 3). 
Embora silenciadas, as questões de gênero atravessam os muros das instituições de saúde e se materializam nos discursos, nas práticas e no cotidiano dos trabalhadores, ainda que de um modo velado e quase imperceptível. Com seus discursos 'genderificados', profissionais e gestores (re)produzem nos serviços de saúde estereótipos e ideologias de uma sociedade em que as diferenças sexuais são transformadas em instrumentos de desigualdades sociais (Schraiber, 2012).

Nessa direção, conforme destaca uma das participantes, em uma cultura em que o homem é considerado como forte e invulnerável, e a mulher é reconhecida pela sua suposta fragilidade e sensibilidade, é recorrente que as ações assistenciais estejam voltadas para os indivíduos representados como vulneráveis - transformados, portanto, em sujeitos das políticas públicas:

Eu acho que a gente sempre pensa em homem como o ser forte, dominador! Que não precisa de cuidado. Aí, quando a gente pensa em cuidado, pensa em criança, gestante, mulher, idoso e deficiente, pensa que são as classes mais vulneráveis entre aspas (P. 10).

O não reconhecimento dos homens como sujeitos do cuidado e das políticas públicas favorece a sua desqualificação como possível beneficiário das propostas assistenciais (Toneli e Müller, 2011; Couto et al., 2010). Como prática social, a assistência à saúde encontra-se atravessada pelo processo de divisão sexual do cuidado, contribuindo assim para o delineamento de práticas voltadas para um grupo de sujeitos e a ausência de ações direcionadas a outros (Lago e Müller, 2010).

As(Os) entrevistadas(os) constataram a maior ênfase da assistência em saúde direcionada às mulheres, já que, conforme anteriormente destacado, referem-se a um público que supostamente mais necessitaria do cuidado. Assim, enquanto as mulheres são bombardeadas pelos apelos das equipes de saúde para se vincularem às ações propostas, os homens são muitas vezes esquecidos e negligenciados, conforme ressaltam as(os) entrevistadas(dos) a seguir:

É engraçado! Se de seis em seis meses ou de doze em doze meses ela [sua esposa] tem que fazer mamografia, o posto liga: "Olha, tá vencendo o seu último exame aí, ó. Tá aproximando a data aí" (P. 3).

Você vai em um posto de saúde, você vê muito pedido para as mulheres comparecerem ao exame ginecológico... não tem isso pra homem! Eu nunca vi! (...) nos postos de saúde você vê assim, ó: "Exame preventivo!" "Mulher: previna-se!" "Exame Papanicolau!" "Prevenção do câncer de colo do útero" (...). Você não vê nada pra homem, não! (...) Eu nunca vi nada: "Homens, venham! Apareçam!" Né?! "Faça o exame tal!" Não, não tem (P. 1). 
Conforme destaca um dos entrevistados, a assistência que prioriza as demandas e necessidades das mulheres refere-se a uma prática já instituída e naturalizada, não é objeto de questionamentos de equipes ou gestores em saúde. Soma-se ainda o maior preparo e familiaridade dos profissionais de saúde com a assistência voltada às mulheres, com o reforço da maior adesão delas às propostas de cuidado. Um dos entrevistados afirma:

Talvez não seja nem questão de escolha. Talvez seja um padrãozinho já estabelecido. (...) se nós atendermos as mulheres, nós estamos exercendo já a nossa função muito bem, ninguém vai reclamar! Então, eu penso que é uma tradição, um tradicionalismo, (...) é até involuntário, já tá cauterizado nas nossas cabeças (P. 3).

Resultados semelhantes são apontados na literatura, em que se observa um incipiente reconhecimento dos homens como sujeitos das ações de saúde e invisibilidade desse público nos serviços de atenção básica (Couto et al., 2010; Gomes et al., 2011). As concepções de gênero de profissionais e gestores também vêm sendo consideradas como importantes elementos que contribuem para a invisibilidade masculina nos serviços de saúde; reforçam os estereótipos que associam as mulheres ao âmbito do cuidado; e fortalecem o processos de (re)produção de desigualdades de gênero no contexto institucional (Machin et al., 2011).

Segundo Martins e colaboradores (2012), os homens exigem das equipes de saúde um modo distinto de atuação que requer a reinvenção de novos modos de pensar, sentir e agir em saúde que ainda não integram a formação básica e continuada dos profissionais brasileiros. Na mesma direção, Schraiber (2012) ressalta a necessidade de se fomentarem nos próprios serviços de saúde dispositivos que possibilitem a reflexão dos trabalhadores acerca do processo de 'genderificação' da prática profissional.

Embora a PNAISH preconize o desenvolvimento de iniciativas que reconheçam as implicações das masculinidades nas práticas assistenciais, constata-se que ela ainda carece de maior divulgação e discussão no âmbito dos serviços de saúde (Leal, Figueiredo e Silva, 2012). No presente estudo, todos os entrevistados afirmaram desconhecer a existência de uma política pública que fomentasse e garantisse o desenvolvimento de ações voltadas para a população masculina, conforme as falas a seguir: “Não (...) eu nem sabia que homem tem política de saúde. Porque a gente sempre fala da mulher, da criança e do idoso" (P. 10); “Não. Do homem? Não! Nunca ouvi falar" (P. 8).

Estudos apontam que, apesar de instituída a PNAISH, seus objetivos ainda encontram-se distantes dos espaços de formação e das práticas assistenciais em saúde (Gomes et al., 2011; Knauth, Couto e Figueiredo, 2012). Embora desconhecendo os princípios e diretrizes da PNAISH, as(os) entre- 
vistadas(os) afirmam que a implantação de uma política de saúde para os homens vai além da simples mobilização desse público para os serviços assistenciais. Exige ainda a reformulação dos processos de trabalho e a reorganização das propostas de cuidado ainda marcados por carência de profissionais, trabalho precarizado e uma formação distanciada da realidade dos serviços.

A necessidade de construção de novos arranjos organizacionais e a importância de se considerarem os aspectos institucionais foram destacadas por algumas das entrevistadas:

A gente trabalha com um número extremamente restrito de funcionários. Eu acho que a proposta é muito boa [PNAISH], mas eu não sei se a gente teria tempo pra fazer isso (P. 2).

Às vezes, a gente não tem muito tempo pra dar essa abertura, essa atenção pro paciente. Eu até gostaria. Às vezes, eu nem fico puxando muito determinado assunto com o paciente, porque se prolongar muito eu tenho que atender o andar, eu tenho que atender ambulatório; então, às vezes sou bem específica (P. 6).

É preciso considerar que a 'clínica degradada', marcada pela precarização dos processos e recursos de trabalho, ainda é uma realidade recorrente em muitos serviços de saúde do país (Campos, 2003). Desse modo, a inclusão de novos sujeitos na pauta assistencial, nesse caso os homens, vem sendo percebida por profissionais e equipes de saúde como uma sobrecarga de trabalho difícil de ser suportada (Alvarenga et al., 2012; Martins et al., 2012; Knauth, Couto e Figueiredo, 2012).

Tornam-se imprescindíveis o engajamento e a implicação dos gestores no delineamento de processos organizacionais que favoreçam a implantação da PNAISH, de modo que ela não seja percebida pelos trabalhadores do SUS como um serviço extra que sobrecarrega e inviabiliza a assistência e as práticas de cuidado. O investimento em espaços de formação profissional que considerem as questões de gênero, associado à reorganização dos processos de trabalho, poderá contribuir para a (re)criação de propostas assistenciais que favoreçam a inclusão da população masculina nos serviços de saúde e, ao mesmo tempo, garantam a resolubilidade e a integralidade da assistência.

\section{Considerações finais}

Apesar do crescimento contínuo da produção de conhecimento sobre a temática da saúde do homem e dos esforços recentes para o delineamento de uma política púbica que considere as singularidades da população masculina, 
a implantação de ações voltadas para os homens nos serviços de saúde ainda se configura como um grande desafio.

Conforme se pôde observar nas falas dos entrevistados, os homens ainda constroem e exercitam suas masculinidades em uma cultura marcada pelas desigualdades de gênero que os distanciam das práticas de cuidado e dos serviços de saúde. De forma semelhante, os profissionais de saúde também se encontram atravessados por estereótipos de gênero, (re)produzindo assim um discurso que não reconhece os homens como sujeitos das políticas de saúde e ações assistenciais e que valoriza o atendimento do público materno-infantil.

Constata-se que as concepções de gênero dos profissionais entrevistados impregnam o seu discurso, orientando seus modos de pensar e sentir, materializando-se tanto nas práticas assistenciais ofertadas quanto nas iniciativas negadas e negligenciadas. Embora reconheçam as especificidades dos modos como os homens vivenciam o adoecimento pelo câncer e se vinculam ao tratamento oncológico, os participantes apontam para a inexistência de ações que considerem as singularidades do público masculino. No entanto, eles reconhecem a maior ênfase dada às necessidades das mulheres, refletindo o processo de divisão sexual do cuidado e a 'genderificação' das instituições de saúde.

Os dados do presente estudo somam-se a outros achados na literatura que indicam a urgência de investimento na divulgação da PNAISH e, especialmente, a implantação de espaços de discussão sobre essa política nos serviços assistenciais. A análise das concepções das(os) profissionais sobre o tema da saúde do homem e acerca da implantação da PNAISH revela a necessidade de investimento em processos formativos que possibilitem a reconstrução dos modos de pensar, sentir e agir das equipes de saúde, buscando a construção de propostas assistenciais mais participativas e horizontalizadas.

Por fim, acredita-se que o desenvolvimento de ações em saúde para os homens requer o delineamento de processos organizacionais inovadores, que desafiem os modelos assistenciais instituídos e abram espaço para a criação e a (re)invenção de práticas, olhares e metodologias. Tal desafio e sua complexidade revelam a necessidade de trilharmos caminhos ainda pouco familiares às equipes de saúde, passando pelas veredas da intersetorialidade, do trabalho em rede e da participação popular. Em outras palavras, abrem espaço para novos estudos e o desenvolvimento de práticas que não percam de vista uma sociedade equânime, justa e saudável.

Os resultados apresentados neste artigo se referem aos modos de pensar, sentir e agir de uma equipe de profissionais de saúde de um serviço de oncologia. Novos estudos poderão ser realizados para analisar as concepções de outros trabalhadores e gestores, de diferentes categorias e formações profissionais, possibilitando assim ampliar o debate sobre a temática para novos espaços. 


\title{
Colaboradores
}

\author{
Alberto Mesaque Martins participou da concepção da pesquisa, coleta e \\ análise dos dados e redação do texto final. Celina Maria Modena participou \\ da concepção da pesquisa, orientação da coleta e análise dos dados e \\ redação do texto final.
}

Resumen En la perspectiva de la investigación cualitativa y de las teorías de género, este estudio tiene como objetivo identificar y analizar las concepciones de profesionales de la salud que actúan en un equipo multidisciplinario en oncología acerca de la asistencia ofrecida al público masculino con cáncer. Fueron entrevistados diez profesionales de la salud que componen un equipo multidisciplinario de un hospital oncológico de Belo Horizonte, en Minas Gerais, Brasil. Los resultados indican que, para los entrevistados, los hombres se caracterizan como público resistente y de difícil actuación, exigiendo una asistencia distinta de aquella ofrecida a las mujeres. La dimensión biológica y el proceso de socialización fueron apuntados como elementos que contribuyen para ese distanciamiento. Además, se constató que los discursos de los profesionales de la salud también se encuentran atravesados por estereotipos de género. Se observó mayor énfasis hacia las necesidades de las mujeres y el no reconocimiento de los hombres como sujetos de políticas de salud y acciones asistenciales. Fue necesaria la inclusión del tema de las masculinidades en la pauta de discusiones de los servicios de salud en oncología, favoreciendo la construcción participativa de estrategias que permitan el reconocimiento de las necesidades masculinas y la garantía de prácticas de salud orientadas por el principio de integralidad.

Palabras clave neoplasias; género; salud del hombre; asistencia.

\section{Notas}

1 Fundação Oswaldo Cruz, Centro de Pesquisas René Rachou, Belo Horizonte, Minas Gerais, Brasil.

$<$ albertomesaque@yahoo.com.br>

Correspondência: Av. Augusto de Lima, 1715, Barro Preto, CEP 33190-002, Belo Horizonte, Minas Gerais, Brasil.

2 Fundação Oswaldo Cruz, Centro de Pesquisas René Rachou, Belo Horizonte, Minas Gerais, Brasil.

$<$ celina@cpqrr.fiocruz.br>

3 O texto da PNAISH encontra-se disponível para leitura em: <http://bvsms.saude.gov. br/bvs/publicacoes/politica_nacional_atencao_saude_homem.pdf>. Acesso em: 18 maio 2012.

4 Pesquisa financiada pela Fundação de Amparo à Pesquisa do Estado de Minas Gerais (Fapemig). 


\section{Referências}

ALVARENGA, Willyane A. et al. Política de saúde do homem: perspectivas de enfermeiras para sua implementação. Revista Brasileira de Enfermagem, Brasília, v. 65, n. 6, p. 929-935, 2012.

AQUINO, Estela M. Saúde do homem: uma nova etapa da medicalização da sexualidade? Ciência \& Saúde Coletiva, Rio de Janeiro, v. 10, n. 1, p. 19-22, 2005.

AQUINO, Estela M. Gênero e saúde: perfil e tendências da produção científica no Brasil. Revista de Saúde Pública, São Paulo, v. 40, número especial, p. 121-132, 2006.

ARILHA, Margareth. Nações Unidas, população e gênero: homens em perspectiva. Jundiaí: Editora in House, 2010.

BARDIN, Laurence. Análise de conteúdo. São Paulo: Martins Fontes, 1976.

BEDRIKOW, Rubens; CAMPOS, Gastão W. S. Clínica médica: a arte de equilibrar a doença e o sujeito. Revista da Associação Médica Brasileira, São Paulo, v. 57, n. 6, p. 610-613, 2011.

BRASIL. Mistério da Saúde. Política Nacional de Atenção Integral à Saúde do Homem: princípios e diretrizes. Brasília: Ministério da Saúde, 2009. Disponível em: < http://bvsms. saude.gov.br/bvs/publicacoes/politica_ nacional_atencao_saude_homem.pdf $>$. Acesso em: 18 maio 2012.

BURILLE, Andreia; SCHWARTZ, Eda; ZILLMER, Juliana G. V. Mudanças no cotidiano de homens com câncer: apresentando uma das interfaces do adoecer. Revista Pesquisa: Cuidado é Fundamental, Rio de Janeiro, v. 5 , n. 2, p. 3.539-3.548, 2013.

BUTLER, Judith. Problemas de gênero: feminismo e subversão de identidade. 3. ed. Rio de Janeiro: Civilização Brasileira, 2011.

CAMARGO JUNIOR, Kenneth R. Um ensaio sobre a (in)definição da integralidade. In:
PINHEIRO, Roseni; MATTOS, Ruben A. (orgs.). Construção da integralidade: cotidiano, saberes e práticas em saúde. 5. ed. Rio de Janeiro: Cepesc, 2010. p. 37-46.

CAMPOS, Gastão W. S. A clínica do sujeito: por uma clínica reformulada e ampliada. In: CAMPOS, Gastão W. S. Saúde Paideia. São Paulo: Hucitec, 2003. p. 51-67.

CARRARA, Sérgio; RUSSO, Jane A.; FARO, Livi. A política de atenção à saúde do homem no Brasil: os paradoxos da medicalização do corpo masculino. Physis: Revista de Saúde Coletiva, Rio de Janeiro, v. 19, n. 3, p. 659-678, 2009.

CECILIO, Luiz C. O. Apontamentos teórico-conceituais sobre processos avaliativos considerando as múltiplas dimensões da gestão do cuidado em saúde. Interface: Saúde, Educação, Comunicação, Botucatu, v. 15, n. 37, p. 589-599, 2011.

CONNEL, Raewyn; MESSERSCHMIDT, James. Masculinidade hegemônica: repensando o conceito. Estudos Feministas, Florianópolis, v. 21, n. 1, p. 241-282, 2013.

CONNEL, Robert W. Políticas da masculinidade. Educação \& Realidade, Porto Alegre, v. 20, n. 2, p. 185-206, 1995.

COUTO, Márcia T.; GOMES, Romeu. Homens, saúde e políticas públicas: a equidade de gênero em questão. Ciência \& Saúde Coletiva, Rio de Janeiro, v. 17, n. 10, p. 2.569-2.578, 2012.

COUTO, Márcia Thereza et al. O homem na atenção primária à saúde: discutindo (in)visibilidade a partir da perspectiva de gênero. Interface: Comunicação, Saúde, Educação, Botucatu, SP, v. 14, n. 33, p. 257-270, 2010.

DAZIO, Eliza M. R.; SONOBE, Helena M.; ZAGO, Márcia M. F. Os sentidos de ser homem com estoma intestinal por câncer colorretal: uma abordagem na antropologia das masculinidades. Revista Latino-Ameri- 
cana de Enfermagem, Ribeirão Preto, v. 17, n. 5, p. 664-669, 2009.

FIGUEIREDO, Wagner S.; SCHRAIBER, Lilia B. Concepções de gênero de homens usuários e profissionais de saúde de serviços de atenção primária e os possíveis impactos na saúde da população masculina, São Paulo, Brasil. Ciência \& Saúde Coletiva, Rio de Janeiro, v. 16, supl. 1, p. 935-944, 2011.

FONTANELLA, Bruno J. B.; RICAS, Janete; TURATO, Egberto R. Amostragem por saturação em pesquisas qualitativas em saúde: contribuições teóricas. Cadernos de Saúde Pública, Rio de Janeiro, v. 24, n. 1, p. 17-27, 2008.

GANNON, Kenneth et al. Re-construction masculinity following radical prostatectomy for prostate cancer. The Aging Male, London, v. 13, n. 4, p. 258-264, 2010.

GOMES, Romeu. Sexualidade masculina, gênero e saúde. Rio de Janeiro: Editora Fiocruz, 2008. (Coleção Criança, Mulher e Saúde).

GOMES, Romeu et al. Os homens não vêm! Interpretação dos profissionais de saúde sobre ausência e/ou invisibilidade masculina nos serviços de atenção primária do Rio de Janeiro. Ciência \& Saúde Coletiva, Rio de Janeiro, v. 16, supl. 1, p. 983-992, 2011.

JARDIM, Denise F. Performances, reprodução e produção dos corpos masculinos. In: LEAL, Ondina F. (org.). Corpo e significado: ensaios de antropologia social. Porto Alegre: Editora da UFRGS, 1995. p. 193-205.

KELLY, Daniel. Changed men: the embodied impact of prostate cancer. Qualitative Health Research, Salt Lake City, v. 19, n. 2, p. 151-163, 2009.

KIMMEL, Michael. A produção simultânea de masculinidades hegemônicas e subalternas. Horizontes Antropológicos, Porto Alegre, v. 9, n. 4, p. 103-117, 1998.

KNAUTH, Daniela R.; COUTO, Márcia T.; FIGUEIREDO, Wagner S. A visão dos profissionais sobre a presença e as demandas dos homens nos serviços de saúde: perspectivas para a análise da implantação da Política Nacional de Atenção Integral à Saúde do Homem. Ciência \& Saúde Coletiva, Rio de Janeiro, v. 17, n. 10, p. 2.617-2.626, 2012.

KUHNEN, Tânia. É possível dizer algo novo sobre essencialismo de gênero? Revista Estudos Feministas, Florianópolis, v. 21, n. 1, p. 409-412, 2013.

LAGO, Mara C. S.; MÜLLER, Rita C. F. O sujeito universal do cuidado no SUS: gênero, corpo e saúde nas falas de profissionais e usuários do Hospital Universitário - Florianópolis, Santa Catarina. In: STREY, Marlene N.; NOGUEIRA, Conceição; AZAMBUJA, Mariana R. Gênero e Saúde: diálogos ibero-brasileiros. Porto Alegre: EdiPUCRS, 2010. p. 279-302.

LEAL, Andrea Fachel; FIGUEIREDO, Wagner S.; SILVA, Geórgia S. N. O percurso da Política Nacional de Atenção Integral à Saúde dos Homens (PNAISH), desde a sua formulação até sua implementação nos serviços públicos locais de atenção à saúde. Ciência \& Saúde Coletiva, Rio de Janeiro, v. 17, n. 10, p. 2.607-2.616, 2012.

LYRA, Jorge et al. Homens e gênero: desafios na construção de uma agenda de política de saúde. Boletim do Instituto de Saúde, São Paulo, v. 14, n. 1, p. 7-15, 2012.

MACHIN, Rosana et al. Concepções de gênero, masculinidade e cuidados em saúde: um estudo com profissionais de saúde da atenção primária. Ciência \& Saúde Coletiva, Rio de Janeiro, v. 16, n. 11, p. 4.503-4.512, 2011.

MARQUES, António Manuel. Gênero e saúde: uma relação ainda oculta. In: STREY, Marlene N.; NOGUEIRA, Conceição; AZAMBUJA, Mariana R. Gênero e Saúde: diálogos ibero-brasileiros. Porto Alegre: EdiPUCRS, 2010. p. 35-58.

MARTINS, Alberto M.; MALAMUT, Bernardo S. Análise do discurso da Política Nacional de Atenção Integral à Saúde do Homem. Saúde e Sociedade, São Paulo, v. 22, n. 2, p. 429-440, 2013. 
MARTINS, Alberto M. et al. Concepções de psicólogos sobre o adoecimento de homens com câncer. Psicologia: Teoria e Prática, São Paulo, v. 14, n. 2, p. 74-87, 2012.

MARTINS, Alberto M. et al. A assistência psicológica aos homens com câncer: reflexões na perspectiva de gênero. Revista da $S B P H$, Belo Horizonte, v. 16, p. 49-69, 2013.

MATTOS, Ruben A. Os sentidos da integralidade: algumas reflexões acerca de valores que merecem ser defendidos. In: PINHEIRO, Roseni; MATTOS, Ruben A. (orgs.). Os sentidos da integralidade na atenção e no cuidado à saúde. 8. ed. Rio de Janeiro: Cepesc, 2009. p. 43-68.

MESQUITA, Maria G. F.; MOREIRA, Marléa Chagas; MALISKI, Sally. "But I'm (became) different": cancer generates reriorizations in masculine identity. Cancer Nursing, Salt Lake City, v. 34, n. 2, p. 150-157, 2011.

MINAYO, Maria C. S. O desafio do conhecimento: pesquisa qualitativa em saúde. São Paulo: Hucitec, 2007.

MODENA, Celina M. Câncer e masculinidades: sentidos atribuídos ao adoecimento e ao tratamento oncológico. Temas em Psicologia, Ribeirão Preto, v. 22, n. 1. p. 67-78, 2014.

MÜLLER, Rita C. F. Violência, vulnerabilidade e risco na Política Nacional de Atenção Integral à Saúde do Homem. Revista Epos, Rio de Janeiro, v. 3, n. 2, p. 1-15, 2012.

MÜLLER, Rita C. F. Por uma cartografia do direito do homem à saúde: considerações sobre a Política Nacional de Atenção Integral à Saúde do Homem e a agenda de direitos reprodutivos e sexuais. Conexões Psi, Rio de Janeiro, v. 1, p. 35-56, 2013.

SCHRAIBER, Lilia B. Necessidades de saúde, políticas públicas e gênero: a perspectiva das práticas profissionais. Ciência \& Saúde Coletiva, Rio de Janeiro, v. 17, n. 10, p. 2.635-2.644, 2012.

SCOTT, Joan. Gênero: uma categoria útil de análise histórica. Educação \& Realidade, Porto Alegre, v. 20, n. 2, p. 71-99, 1995.
SILVA, Lúcia C. O cuidado na vivência do doente de câncer: uma compreensão fenomenológica. Maringá: UEM, 2009.

SOARES, Célia; LARANJEIRA, Ana R. O gênero na saúde: discursos e representações de profissionais sobre o contexto português. In: STREY, Marlene N.; NOGUEIRA, Conceição; AZAMBUJA, Mariana R. Gênero e Saúde: diálogos ibero-brasileiros. Porto Alegre: EdiPUCRS, 2010. p. 59-78.

SOUZA, Luís E. P. F. O SUS necessário e o SUS possível: gestão - uma reflexão a partir de uma experiência concreta. Ciência \& Saúde Coletiva, Rio de Janeiro, v. 14, n. 3, p. 911-918, 2009.

TONELI, Maria J. F.; MÜLLER, Rita C. F. A divisão sexual do cuidado com a saúde: homens, mulheres e a economia do gênero nos significados de saúde/doença em Florianópolis/SC. In: TRINDADE, Zeide A.; MENANDRO, Maria C. S.; NASCIMENTO, Célia R. R. (orgs.). Masculinidades e saúde: produção científica e contexto. Vitória: GM Editora, 2011, p. 79-97.

TONELI, Maria J. F.; SOUZA, Marina G. C.; MÜLLER, Rita C. F. Masculinidades e práticas de saúde: retratos da experiência de pesquisa em Florianópolis/SC. Physis: Revista de Saúde Coeltiva, Rio de Janeiro, v. 20, n. 3, p. 973-994, 2010.

VILLELA, Wilza; MONTEIRO, Simone; VARGAS, Eliane. A incorporação de novos temas e saberes nos estudos em saúde coletiva: o caso do uso da categoria gênero. Ciência \& Saúde Coletiva, Rio de Janeiro, v. 14, n. 4, p. 997-1.006, 2009.

XAVIER, Antonia T. F. et al. Análise de gênero para o adoecer de câncer. Revista Brasileira de Enfermagem, Brasília, v. 63, n. 6, p. 921-926, 2010.

Recebido em 18/03/2013

Aprovado em 25/09/2015 